\title{
COMPARATIVE STUDY OF LIPOPHILIC EXTRACTIVES OF HARDWOODS AND CORRESPONDING ECF BLEACHED KRAFT PULPS
}

\author{
Carmen S. R. Freire, Paula C. R. Pinto, Ana S. Santiago, Armando J. D. Silvestre, Dmitry
} V. Evtuguin and Carlos Pascoal Neto*

\begin{abstract}
The lipophilic extractives of Eucalyptus globulus, Eucalyptus grandis, Eucalyptus urograndis, Betula verrucosa and Acacia mangium woods and of the corresponding ECF bleached kraft pulps, were characterized by GC-MS. The five hardwoods showed significant differences in the content and composition of the main families of extractives, namely fatty acids, long chain aliphatic alcohols and sterols. Significant differences in the composition persist after wood pulping and ECF bleaching of pulps. The fate of the various types of extractives during the wood and pulp processing is discussed. Long chain aliphatic acids and alcohols are quite stable during the pulp production and are retained to a great extent in the final bleached pulp; $\Delta^{5}$ sterols are mostly oxidized and partially retained in the pulps, while $\Delta^{7}$ sterols are completely degraded and/or dissolved. $B$. verrucosa and $A$. mangium bleached pulps show contents of fatty acids about 4 and 20 times higher than that of Eucalyptus pulps, respectively, while the content of long chain aliphatic alcohols in $A$. mangium pulp is of the order of 100 times higher than Eucalyptus and $B$. verrucosa pulps.
\end{abstract}

Keywords: Lipophilic extractives; Hardwoods; Eucalyptus; Betula; Acacia; GC-MS analysis; ECF bleaching

Contact information: CICECO and Department of Chemistry, University of Aveiro, 3810-193 Aveiro, Portugal; *Corresponding author: cneto@dq.ua.pt

\section{INTRODUCTION}

Plantation hardwoods such as Eucalyptus globulus, Eucalyptus grandis and Eucalyptus urograndis, represent nowadays the major fiber sources for the pulp and paper industry in the Iberian Peninsula and South America (Hillman 2002). Acacia species, namely Acacia mangium, are also becoming important wood sources for the pulp-and-paper industry in the Asiatic region (Coleman 1998; Hillman 2002).

The lipophilic fraction of wood extractives, even present in small amounts in wood, may play an important role in pulp and paper production (Back and Allen 2000). The concentration and composition are determinants in the efficiency of pulping and bleaching processes. The extractives retained in the bleached pulp may affect significantly the physico-chemical properties of fibers, such us their surface energy, and contribute to pitch deposition in the papermaking process (Back and Allen 2000).

E. globulus wood extractives have been studied extensively (Swan and Åkerblom 1967; Santos et al. 1997; Wallis and Wearne 1997; Gutíerrez et al. 1998, 1999; Freire et 
al. 2002a), as well as their behavior during kraft pulping and bleaching processes (Gutiérrez et al. 2001a; Gutíerrez et al. 2001b; Freire et al. 2003, 2005, 2006) and their relationship with pitch composition (Gutiérrez et al. 1998; del Río et al. 1998, 2000, Silvestre et al. 1999; Freire et al. 2002b, 2005). However, to our knowledge no significant investigations related to E. urograndis and E. grandis have been reported. In addition, only a few studies on the chemical composition of Acacia mangium wood (Pietarinen et al. 2003) have been published. Recently, a study of the surface and bulk composition of bleached kraft pulps of Eucalyptus globulus, Eucalyptus grandis and Eucalyptus urograndis, Acacia mangium and Betula verrucosa has been published (Pascoal Neto et al. 2004), pointing out significant differences in pulps compositions.

In the present study, the lipophilic extractives of these five hardwoods species were extensively characterized. The corresponding DEDED bleached kraft pulps were also analyzed for their lipophilic extractives, aiming to assess the fate of the different components during kraft pulping and ECF bleaching processes and the potential impact of extractives content and composition of bleached fibers on their properties and on the papermaking process.

\section{EXPERIMENTAL}

\section{Samples}

Eucalyptus globulus wood was selected from an industrial clone plantation cultivated in the region of Aveiro, Portugal. Eucalyptus urograndis and Eucalyptus grandis industrial woods were issued from Brazil. Betula verrucosa and Acacia mangium woods were obtained from pulp industries in Sweden and Indonesia, respectively.

Representative chip samples of the different wood species were ground and sieved, and the granulometric fraction of 40-60 mesh was used for analysis.

Wood chips of industrial size were kraft pulped to kappa number 15-16 in a laboratory circulation batch digester (Table 1); the pulps were then bleached $(90 \%$ ISO brightness) by a conventional Elemental Chlorine Free (ECF) sequence (DEDED), using standard conditions, and then washed until $\mathrm{pH} \sim 7$ and dried at room temperature before extraction.

Table 1. Conditions and Results of Kraft Pulping of the Different Hardwoods and $\mathrm{ClO}_{2}$ Consumption During the ECF Bleaching of the Corresponding Kraft Pulps.

\begin{tabular}{|c|c|c|c|c|c|}
\hline & E. globulus & E. urograndis & E. grandis & B. verrucosa & A. mangium \\
\hline \multicolumn{6}{|l|}{ Kraft pulping* $^{*}$} \\
\hline Active alkali, $\% \mathrm{Na}_{2} \mathrm{O}$ & 16 & 20 & 19 & 18 & 24 \\
\hline Time at temperature, min & 50 & 65 & 60 & 65 & 65 \\
\hline Pulp yield, \%/ wood & 55.6 & 49.6 & 50.6 & 49.8 & 51.1 \\
\hline Kappa number & 15.0 & 15.7 & 16.1 & 16.4 & 15.9 \\
\hline Viscosity, $\mathrm{ml} / \mathrm{g}$ & 1460 & 1130 & 1190 & 1340 & 990 \\
\hline \multicolumn{6}{|l|}{ ECF bleaching (90\% ISO) } \\
\hline $\mathrm{ClO}_{2}$ consumption, $\% /$ pulp & 4.4 & 5.4 & 5.3 & 7.2 & 7.4 \\
\hline
\end{tabular}




\section{Extraction}

The ground wood samples (three replicates of $20 \mathrm{~g}$ ) were Soxhlet extracted with dichloromethane for 6 hours, while the bleached pulps (three replicates of $20 \mathrm{~g}$ ) were Soxhlet extracted with acetone for 6 hours. Dichloromethane was selected as the solvent for wood instead of acetone because of its selectivity for lipophilic components, simplifying the analysis of the complex wood extracts. However, the nature and amount of lipophilic compounds extracted from the bleached pulps with the two solvents is similar, as confirmed by preliminary analysis, allowing the comparison of wood and bleached pulp lipophilic extractives composition. Acetone was used in the case of pulps in order to be consistent with the procedures used in a wider research project. The solvents were evaporated to dryness and the extracts were weighed. The results were reported as weight percent of the respective dry woods or pulps.

\section{GC-MS Analysis}

The GC-MS analysis and quantification of the major lipophilic wood and bleached pulps extractives (before and after alkaline hydrolysis in the case of wood) were performed as previously described (Freire et al. 2002a). Nearly $20 \mathrm{mg}$ of each dried sample were trimethylsilylated (Ekman 1983a) and injected three times. GC-MS analyses were performed using a Trace Gas Chromatograph 2000 Series equipped with a Finnigan Trace MS mass spectrometer, using helium as carrier gas $(35 \mathrm{~cm} / \mathrm{s})$, equipped with a DB-1 J\&W capillary column (30 m x $0.32 \mathrm{~mm}$ i.d., $0.25 \mu \mathrm{m}$ film thickness). The chromatographic conditions were as follows: initial temperature: $80{ }^{\circ} \mathrm{C}$ for $5 \mathrm{~min}$; temperature rate: $4{ }^{\circ} \mathrm{C} / \mathrm{min}$; final temperature: $285^{\circ} \mathrm{C}$ for $10 \mathrm{~min}$; injector temperature: $290^{\circ} \mathrm{C}$; transfer-line temperature: $290^{\circ} \mathrm{C}$; split ratio: $1: 100$.

In order to verify the presence of esterified structures such as triglycerides, steryl esters, waxes and ferulic acid esters, the extracts were also analyzed by GC-MS, using a short length column (DB-1 J\&W capillary column of $15 \mathrm{~m}$ x $0.32 \mathrm{~mm}$ i.d., $0.25 \mu \mathrm{m}$ film thickness). The chromatographic conditions were as follows: initial temperature: $100{ }^{\circ} \mathrm{C}$ for $3 \mathrm{~min}$; temperature rate: $5{ }^{\circ} \mathrm{C} / \mathrm{min}$; final temperature: $340{ }^{\circ} \mathrm{C}$ for $12 \mathrm{~min}$; injector temperature: $320{ }^{\circ} \mathrm{C}$; transfer-line temperature: $290{ }^{\circ} \mathrm{C}$; split ratio: $1: 100$. The partial chromatograms of the dichloromethane hardwoods extracts, obtained using this column, are presented in Fig. 1.

For quantitative analysis, the GC-MS was calibrated with pure reference compounds, representative of the major lipophilic extractives components, namely, hexadecanoic acid (97 \% purity, Fluka Chemie, Madrid, Spain), 1-eicosanol (98 \% purity, Fluka Chemie, Madrid, Spain),, 16-hydroxyhexacosanoic acid, 2hydroxyoctadecanoic acid, stigmasterol (95\% purity, Sigma Chemicals Co., Madrid, Spain) and ferulic acid (99\% purity, Sigma Chemicals Co., Madrid, Spain), relative to tetracosane (99\% purity, Sigma Chemicals Co., Madrid, Spain), the internal standard used. The respective multiplication factors needed for the quantification of the peak areas were calculated as an average of six GC-MS runs.

Compounds were identified, as TMS derivatives, by comparing their mass spectra with the GC-MS spectral library, with data from the literature and in some cases, by injection of standards. 
The approximate percentage of extractives removal from wood during the pulping and bleaching processes was calculated assuming the kraft pulping yields (Table 1) and neglecting the yield losses during the bleaching of pulps.

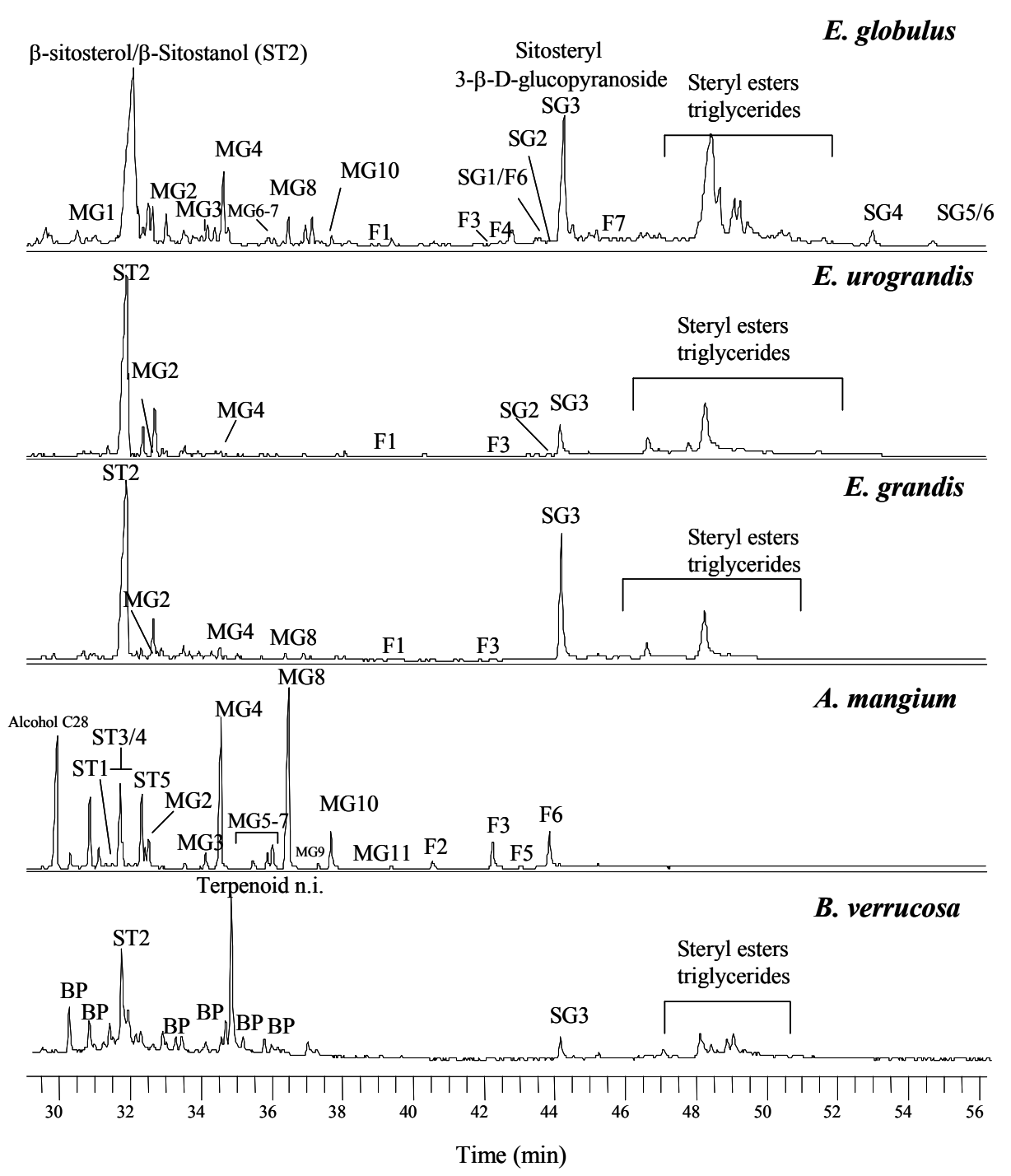

Fig. 1. Partial ion chromatogram, obtained using a short length column $(15 \mathrm{~m})$, of the derivatized dichloromethane extracts of $E$. globulus, $E$. urograndis, E. grandis, A. mangium and B. verrucosa woods. MG1- 1-monodocosanoylglycerol, MG2- 1-monotetracosanoyl glycerol, MG3- 2-hexacosanoylglycerol, MG4- 1-monohexacosanoylglycerol, MG5- 2-mono(24-hydroxytetracosanoyl)glycerol, MG6- 1mono(24-hydroxytetracosanoyl)glycerol, MG7- 2-mono-octacosanoylglycerol, MG8- 1-mono-octacosanoylglycerol, MG9- 2- mono(26-hydroxyhexacosanoyl)glycerol, MG10- 1-mono(26-hydroxyhexacosanoyl)glycerol, MG11- 1-mono(28-hydroxyoctacosanoyl)glycerol; F1- docosanyl ferulate, F2- tetracosanyl ferulate F3-hexacosanyl ferulate, F4- feruloyloxydocosanoic acid, F5- heptacosanyl ferulate, F6- octacosanyl ferulate and F7- feruloyloxyhexacosanoic acid; ST1- 24 -methyl-5 $\alpha$-cholest-7-en-3 $\beta$-ol ST2- $\beta$-sitosterol + $\beta$ sitostanol, ST3- 24-ethyl-5 $\alpha$-cholest-7, trans 22-dien-3 $\beta$-ol , ST4- ergosterol (or an isomer), ST5-24-ethyl-5 $\alpha$ cholest-7-en-3 $\beta$-ol; SG1- campesteryl 3- $\beta$ - $D$-glucopyranoside, SG2- stigmasteryl 3- $\beta$ - $D$-glucopyranoside, SG3- sitosteryl 3- $\beta$-D-glucopyranoside, SG4- sitosteryl (6'-O-palmitoyl)-3- $\beta$-D-glucopyranoside, SG5sitosteryl (6'-O-linoleoyl)-3- $\beta$-D-glucopyranoside, SG6- sitosteryl (6'-O-oleoyl)-3- $\beta$ - $D$-glucopyranoside BPbetulaprenols. 
Table 2. Families of Lipophilic Components Identified in the Dichloromethane Extracts of Woods and Their Contents Before (BH) and After (AH) Alkaline Hydrolysis of the Extract (mg of compound/kg o.d. wood.)

\begin{tabular}{|c|c|c|c|c|c|c|c|c|c|c|}
\hline \multirow[t]{2}{*}{ Family } & \multicolumn{2}{|c|}{ E. globulus } & \multicolumn{2}{|c|}{ E. urograndis } & \multicolumn{2}{|c|}{ E. grandis } & \multicolumn{2}{|c|}{ B. verrucosa } & \multicolumn{2}{|c|}{ A. mangium } \\
\hline & $\mathrm{BH}$ & $\mathrm{AH}$ & $\mathrm{BH}$ & $\mathrm{AH}$ & $\mathrm{BH}$ & $\mathrm{AH}$ & $\mathrm{BH}$ & $\mathrm{AH}$ & $\mathrm{BH}$ & $\mathrm{AH}$ \\
\hline Fatty acids & & & & & & & & & & \\
\hline Saturated & 130.0 & 288.6 & 172.5 & 393.4 & 334.4 & 351.9 & 1426.1 & 1503.0 & 1379.9 & 4623.3 \\
\hline Unsaturated & 88.8 & 121.1 & 106.0 & 185.9 & 90.5 & 111.2 & 490.4 & 454.0 & 40.6 & 66.5 \\
\hline Diacids & 10.2 & 29.0 & 0.00 & 15.0 & 5.75 & 10.9 & 400.4 & 468.1 & 0.00 & 0.00 \\
\hline$\alpha$-hydroxy & 0.00 & 14.5 & 10.5 & 22.0 & 34.7 & 46.9 & 52.6 & 70.3 & 64.7 & 102.7 \\
\hline$\omega$-hydroxy & 0.00 & 67.7 & 0.00 & 155.8 & 7.27 & 98.4 & 54.4 & 61.8 & 221.2 & 1882.4 \\
\hline Other hydroxy acids & 0.00 & 0.00 & 0.00 & 0.00 & 0.00 & 0.00 & 301.4 & 214.5 & 0.00 & 0.00 \\
\hline Total & 229.0 & 520.9 & 289.0 & 772.1 & 472.6 & 619.3 & 2725.3 & 2771.7 & 1706.4 & 6674.9 \\
\hline \multicolumn{11}{|l|}{ Aromatic compounds } \\
\hline Cinnamic acids (ferulic and coumaric acids) & 0.00 & 59.4 & 0.00 & 223.4 & 1.17 & 86.5 & 8.98 & 15.8 & 7.50 & 572.1 \\
\hline Others & 38.1 & 40.8 & 115.2 & 72.4 & 91.7 & 61.9 & 41.6 & 58.0 & 0.00 & 21.5 \\
\hline Total & 38.1 & 100.2 & 115.2 & 295.8 & 92.87 & 148.4 & 50.58 & 73.8 & 7.50 & 593.6 \\
\hline \multicolumn{11}{|l|}{ Long Chain Aliphatic Alcohols } \\
\hline $\begin{aligned} &<\mathrm{C} 20 \\
&>\mathrm{C} 20\end{aligned}$ & $\begin{array}{l}38.9 \\
0.00\end{array}$ & $\begin{array}{l}43.4 \\
12.9\end{array}$ & $\begin{array}{l}8.29 \\
8.91\end{array}$ & $\begin{array}{l}5.30 \\
382\end{array}$ & $\begin{array}{l}6.14 \\
129\end{array}$ & $\begin{array}{l}11.9 \\
259\end{array}$ & $\begin{array}{l}10.6 \\
714\end{array}$ & $\begin{array}{l}14.9 \\
16.5\end{array}$ & $\begin{array}{c}9.17 \\
16168\end{array}$ & $\begin{array}{c}39.3 \\
18096\end{array}$ \\
\hline Total & 38.9 & 56.3 & 17.20 & 43.50 & 19.04 & 37.8 & 17.74 & 31.4 & 1625.97 & 1848.9 \\
\hline Sterols & 318.5 & 474.4 & 537.4 & 642.1 & 729.8 & 811.2 & 219.8 & 212.2 & 657.4 & 544.9 \\
\hline Betulaprenols/ other terpenes & 10.8 & 9.02 & 0.00 & 0.00 & 0.00 & 16.9 & 174.01 & 109.9 & 0.00 & 0.00 \\
\hline Monoglycerides & 22.0 & 0.00 & 26.4 & 0.00 & 15.6 & 0.00 & 0.00 & 0.00 & 962.6 & 0.00 \\
\hline $\begin{array}{l}\text { Others/ } \\
\text { Unidentified }\end{array}$ & 202.2 & 90.3 & 512.0 & 183.9 & 113.7 & 52.7 & 723.4 & 364.0 & 1323.9 & 553.4 \\
\hline TOTAL & 859.5 & 1251.0 & 1497.2 & 1937.4 & 1443.6 & 1686.3 & 3910.8 & 3563.0 & 6283.8 & 10215.7 \\
\hline
\end{tabular}




\section{RESULTS AND DISCUSSION}

\section{Lipophilic Extractives of Woods}

The dichloromethane extractives of E. globulus, E. grandis and E. urograndis account, respectively, for $0.26 \%, 0.36 \%$ and $0.35 \%$ of dry wood basis. These values are considerably lower than those found for B. verrucosa and A. mangium (1.31 and $1.32 \%$ of dry wood basis, respectively). The lipophilic extractives content found for the $A$. mangium and $B$. verrucosa are in good agreement with the figures reported for Acacia (Pietarinen et al. 2003) and Betula species (Ekman and Holmbom 2000).

Sterols, fatty acids, long chain aliphatic alcohols and aromatic compounds are the main families of compounds found in the lipophilic extracts of these hardwood species. Sterols are among the major lipophilic components of Eucalyptus woods lipophilic extractives, particularly after hydrolysis of the extracts (Table 2). For the other hardwoods, although sterols were also found in significant amounts, they are minor components of the corresponding extracts.
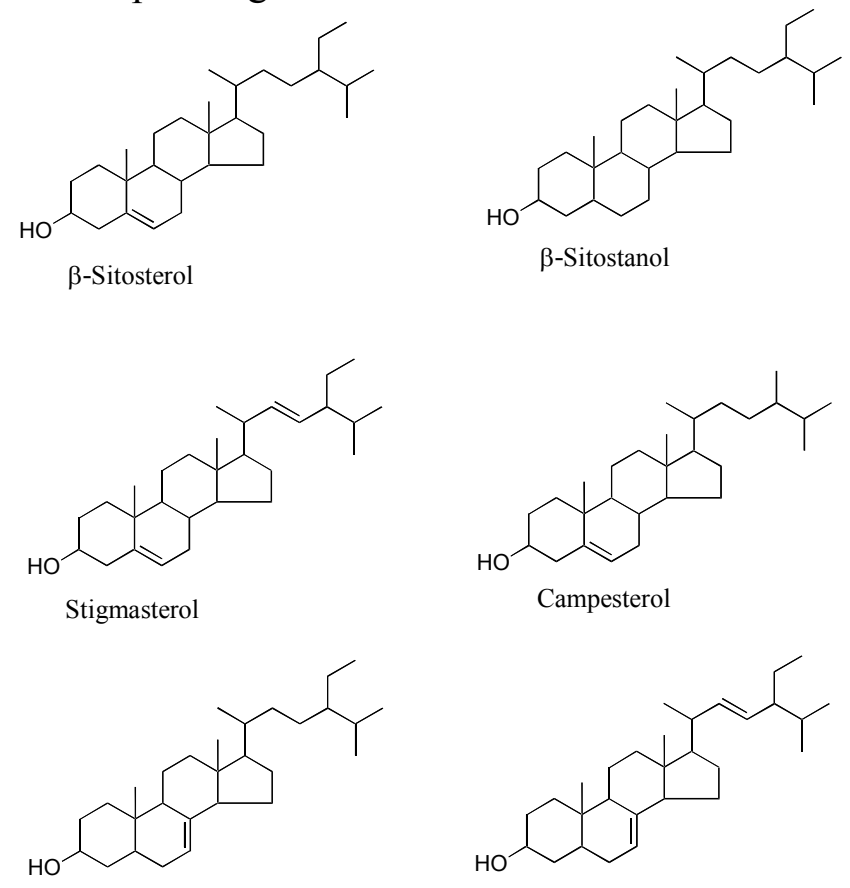

24-Ethyl-5 $\alpha$-cholest-7-en-3 $\beta$-ol (Schottenol)

24-Ethyl-5 $\alpha$-cholest-7,trans 22-dien-3 $\beta$-ol (Spinasterol)
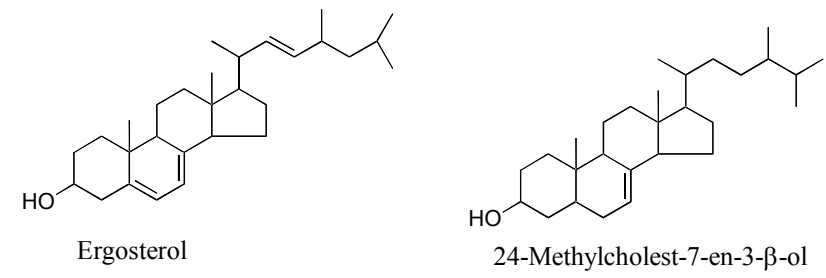

Fig. 2. Structures of the main sterols found in the investigated hardwoods. 
$\beta$-Sitosterol and $\beta$-sitostanol (Fig. 2), the main components of the wood sterols group, were found in all Eucalyptus woods in both free and esterified forms, as confirmed by their increased content observed after alkaline hydrolysis of the extracts (Table 2) as well as by the analysis of the extracts by GC-MS with short columns (Fig. 1). E. grandis and E. urograndis woods contain sterols, particularly free sterols, in larger quantities than in E. globulus. $\beta$-Sitosterol and $\beta$-sitostanol, mostly in the free form, are also the main sterols found in B. verrucosa wood (Table 2, Fig. 1).

Among the major components of the A. mangium extract, two $\Delta^{7}$ sterols (Fig. 2) were identified by EI-MS as 24-ethyl-5 $\alpha$-cholest-7, trans 22 -dien-3 $\beta$-ol and 24-ethyl-5 $\alpha$ cholest-7-en-3 $\beta$-ol (Artaut et al. 1984, Combaut 1986). In addition, small amounts of $24-$ methyl-5 $\alpha$-cholest-7-en-3 $\beta$-ol and ergosterol (or an isomer) were also detected. The $\Delta^{7}$ sterols are not very common wood components, and only 24 -ethyl-5 $\alpha$-cholest-7-en-3 $\beta$-ol and ergosterol have been reported to occur in Acacia species (Pietarinen et al. 2003). The common $\Delta^{5}$ phytosterols, such as stigmasterol and $\beta$-sitosterol (Fig. 2), were not found in the A. mangium lipophilic extract. Recently, the identification of steryl esters in Acacia mangium and Acacia crassicarpa wood has been reported (Pietarinen et al. 2003). We have not detected any steryl esters in our A. mangium wood (Fig. 1). Such differences may be certainly assigned to specific plant growing conditions.

Fatty acids represent the major lipophilic components of the hardwoods investigated in this study (except for E. grandis, where sterols dominate). A. mangium and $B$. verrucosa have a content of these components (Table 2) much higher than in Eucalyptus woods. The qualitative compositions of fatty acids of the five hardwoods also show significant differences between them (Table 2, Fig. 3).

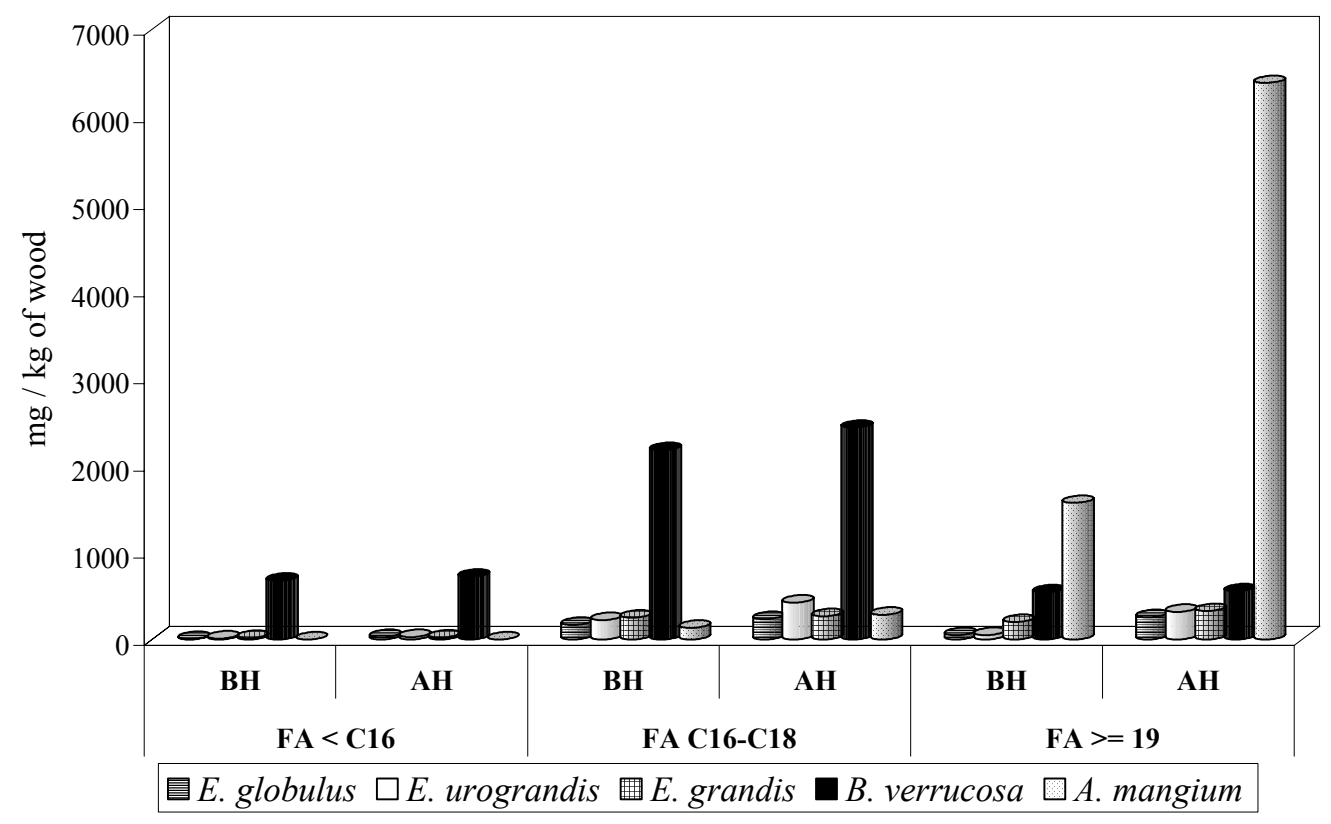

Fig. 3. Major fatty acids present in the dichloromethane extracts of the investigated hardwoods, before $(\mathbf{B H})$ and after alkaline $(\mathbf{A H})$ hydrolysis. FA<C16 fatty acids with less than 16 carbon 
atoms; FA C16-C18 fatty acids with 16 to18 carbon atoms and FA>=19 fatty acids with more than 19 carbon atoms.

Palmitic acid (C16) and the unsaturated oleic (C18:1) and linoleic (C18:2) acids are by far the most abundant fatty acids identified in B. verrucosa wood (Table 2, Fig. 3), as already reported (Ekman and Holmbom 2000). There are considerable amounts of eicosanoic (C20), heneicosanoic (C21) and docosanoic (C22) acids, and of several diacids and acids with less than 16 carbon atoms, such as heptanedioic, octanedioic, azelaic (nonanoic), decanedioic acids and hexanoic, heptanoic, octanoic and nonanoic acids, respectively, were also detected in B. verrucosa wood. All these fatty acids were found to occur almost exclusively in the free form (Table 2, Fig. 3), which is in close agreement with the small amounts of steryl esters and glycerides detected by GC-MS with short columns in this species (Fig. 1), as well as by the small increase observed on the amount of fatty acids detected after alkaline hydrolysis of the extract (Table 2).

On the other hand, Eucalyptus and A. mangium woods contain fatty acids in both free and esterified form as confirmed by the significant increases of fatty acids contents detected after alkaline hydrolysis of the extracts (Table 2, Fig. 3). The long chain tetracosanoic (C24), hexacosanoic (C26) and octacosanoic (C28) acids are the most abundant free and esterified fatty acids present in $A$. mangium wood. The esterified fraction of these fatty acids is largely due to 1-monoglycerides (1-hexacosanoyl glycerol and 1-octacosanoyl glycerol) (Fig.1), as will be discussed below. The common C16-C18 (palmitic, oleic and linoleic acids) fatty acids are minor components of $A$. mangium wood (Fig. 3). However, in the case of Eucalyptus woods extracts, the most abundant free fatty acids are palmitic, oleic and linoleic acids, whereas the esterified fraction is, to a great extent, ascribed to higher fatty acids, as recently reported for E. globulus (Freire et al. 2002a).

The long chain $\alpha$ - and $\omega$ - hydroxy fatty acids, such as 2-hydroxydocosanoic, 2hydroxytetracosanoic and 22-hydroxydocosanoic, 24-hydroxytetracosanoic and 26hydroxyhexacosanoic acids, recently identified in E. globulus wood (Freire et al. 2002a), were also detected in considerable amounts in E. urograndis, E. grandis and A. mangium woods (Table 2). However, in these hardwoods, although the hydroxy fatty acids were mainly detected after alkaline hydrolysis of the extracts, they were also found in free form, whereas in E. globulus, they were detected only after alkaline hydrolysis. The main $\omega$ - and $\alpha$-hydroxy fatty acids found in the dichloromethane extract of $B$. verrucosa wood (before and after alkaline hydrolysis) were 8-hydroxyoctanoic, 9-hydroxynonanoic acids and 2-hydroxyoctanoic, 2-hydroxyhexadecanoic and 2-hydroxytetracosanoic acids, respectively. 2-hydroxydecanedioic and some unknown hydroxyoctadecanoic acids were also detected.

As recently reported by Pietarinen et al. (2003), monoglycerides with C24, C26 and C28 saturated acids represent an important fraction of $A$. mangium wood extracts. In addition, minor amounts of monoglycerides with 24-hydroxytetracosanoic, 26hydroxyhexacosanoic and 28-hydroxyoctacosanoic acids were also detected in our Acacia wood. Eucalyptus woods, particularly E. globulus, also contain monoglycerides with long chain aliphatic acids (> C20) and $\omega$-hydroxy fatty acids. Monoglycerides of C26, C28 and hydroxy fatty acids are reported here for the first time as Eucalyptus woods components and, in the case of E. globulus, can partially explain the high amounts of 
fatty acids with more than $\mathrm{C} 20$ observed after alkaline hydrolysis of the extract. On the other hand, $B$. verrucosa wood contains very small amounts of monoglycerides.

There were diglycerides and triglycerides found in all wood species, comparatively in small amounts with respect to the other families of extractives.

Long chain aliphatic alcohols (free and esterified) represent only a small fraction of the total extractives of the three Eucalyptus woods and of B. verrucosa. However, they represent the second most abundant group of compounds present in the A. mangium wood extract, with 1-tetracosanol, 1-hexacosanol and 1-octacosanol as the main components. Around $12 \%$ of these fatty alcohols are esterified with ferulic acid as confirmed by the identification of considerable amounts of the corresponding ferulates, by GC-MS analysis with short columns (Fig. 1). Ferulic acid esters with fatty alcohols have already been reported to occur in Acacia mangium wood (Pietarinen et al. 2003).

Small amounts of ferulates with C22, C24 and C26 fatty alcohols were also detected in Eucalyptus woods. In addition, two ferulates with $\omega$-hydroxy fatty acids, not identified in the other hardwoods, were also detected in E. globulus wood (Freire et al. 2002a). However, in Eucalyptus woods, ferulates were identified in very small amounts and consequently, could not explain the high amounts of ferulic acid detected after alkaline hydrolysis of the corresponding extracts. Coumaric acid (cis and trans forms) was also detected in considerable amounts, after alkaline hydrolysis of E. grandis and urograndis extracts, although coumaric acid esters were not detected before hydrolysis. The origin of the ferulic and coumaric acids in Eucalyptus woods is under investigation. Vanillic, syringic, vanillin and other aromatics (referred as Aromatic compounds in Table 2) were detected in all hardwoods.

B. verrucosa wood contains considerable amounts of a particular family of terpenes, namely betulaprenols (Table 2) (Ekman and Holmbom 2002). These compounds were not found in the other investigated hardwoods. Only some triterpenic acids, such as oleanolic acid, were identified in small amounts in Eucalyptus extracts.

Finally, sitosteryl 3- $\beta$-D-glucopyranoside, already identified in E. globulus (Gutiérrez et al. 2001b) and Betula species woods (Nilvebrant and Byström 1995), was also detected in considerable amounts in E. urograndis and E. grandis woods. However, no steryl glucosides were detected in A. mangium wood, at least in detectable amounts.

\section{Lipophilic Extractives of ECF Bleached Kraft Pulps}

The acetone extractives found in E. globulus, E. urograndis, E. grandis, $B$. verrucosa and $A$. mangium ECF (DEDED) bleached pulps account for $0.37 \%, 0.16 \%$, $0.27 \%, 0.72 \%$ and $1.53 \%$ of dry pulp basis, respectively. Fatty acids, long chain aliphatic alcohols and sterols keep as the main lipophilic extractives present in the bleached pulps (Table 3). However, significant qualitative and quantitative differences may be pointed out when comparing the different pulps, between them, and with the corresponding wood extractives composition.

Sterols are extensively removed from hardwoods during pulping and ECF bleaching stages. Specifically, around $70 \%, 80 \%, 90 \%, 50 \%$ and $100 \%$ of sterols are removed from E. globulus, E. urograndis, E. grandis, B. verrucosa and A. mangium woods, respectively, during kraft pulping and the DEDED bleaching sequence. 
The major fraction of sterols identified in the Eucalyptus woods and B. verrucosa bleached pulps is ascribed to several oxidation products of $\beta$-sitosterol (Table 3, Fig. 4), recently reported to be the major products from $\beta$-sitosterol oxidation with chlorine dioxide (Freire et al. 2003). $\beta$-Sitostanol is quite abundant in these ECF bleached pulps (Table 3).

Table 3. Families of Lipophilic Components Identified in the Acetone Extracts of the DEDED Bleached Pulps (mg of compound/kg o.d. pulp).

\begin{tabular}{|c|c|c|c|c|c|}
\hline & $\begin{array}{c}E . \\
\text { globulus }\end{array}$ & $\begin{array}{c}E . \\
\text { urograndis }\end{array}$ & $\begin{array}{c}E . \\
\text { grandis }\end{array}$ & $\begin{array}{c}B . \\
\text { verrucosa }\end{array}$ & $\begin{array}{c}A . \\
\text { mangium }\end{array}$ \\
\hline \multicolumn{6}{|l|}{ Fatty acids } \\
\hline Saturated & 502.1 & 340.9 & 262.3 & 2070.1 & 7069.7 \\
\hline Saturated diacids & 8.90 & 20.2 & 8.67 & 38.1 & 146.4 \\
\hline $\begin{array}{l}\alpha \text {-hydroxy } \\
\omega \text {-hydroxy }\end{array}$ & $\begin{array}{l}5.61 \\
85.0\end{array}$ & $\begin{array}{l}29.7 \\
175.9\end{array}$ & $\begin{array}{c}24.1 \\
137.0\end{array}$ & $\begin{array}{l}0.0 \\
0.0\end{array}$ & $\begin{array}{c}102.3 \\
3184.1\end{array}$ \\
\hline dihydroxiacids & 8.74 & 0.0 & 0.0 & 0.0 & 0.0 \\
\hline Total & 610.35 & 566.7 & 432.07 & 2108.2 & 10502.5 \\
\hline Aromatic compounds & 12.5 & 4.45 & 0.876 & 13.1 & 6.3 \\
\hline \multicolumn{6}{|l|}{ Long Chain Aliphatic Alcohols } \\
\hline $\begin{array}{l}<\mathrm{C} 20 \\
>\mathrm{C} 20\end{array}$ & $\begin{array}{l}17.1 \\
19.8\end{array}$ & $\begin{array}{l}12.4 \\
28.1\end{array}$ & $\begin{array}{l}11.8 \\
23.8\end{array}$ & $\begin{array}{l}12.9 \\
7.12\end{array}$ & $\begin{array}{c}18.7 \\
3295.1\end{array}$ \\
\hline Total & 36.9 & 40.5 & 35.6 & 20.02 & 3313.8 \\
\hline \multicolumn{6}{|l|}{ Sterols } \\
\hline$\beta$-Sitosterol & 15.6 & 9.10 & 4.57 & 8.45 & - \\
\hline$\beta$-Sitostanol & 76.1 & 97.3 & 43.1 & 88.3 & - \\
\hline Oxidation products of sterols & 178.6 & 169.2 & 89.43 & 131.3 & - \\
\hline Total & 270.3 & 275.6 & 137.1 & 228.1 & 0.0 \\
\hline Short Chain acids & 27.1 & 12.0 & 8.78 & 68.4 & 383.2 \\
\hline Alkenes & 87.8 & 31.7 & 14.1 & 79.9 & 0.0 \\
\hline Others/Unidentified & 178.8 & 145.7 & 41.2 & 196.3 & 421.7 \\
\hline TOTAL & 1223.8 & 1076.7 & 673.8 & 2714.0 & 14627.5 \\
\hline
\end{tabular}

$\Delta^{7}$ sterols from $A$. mangium wood are completely degraded/removed during kraft pulping and ECF bleaching (Table 3). This behavior could be in part explained by the highest active alkali and $\mathrm{ClO}_{2}$ consumptions observed during pulping and bleaching of $A$. mangium wood (Table 1). However, in the case of $B$. verrucosa wood, the active alkali and $\mathrm{ClO}_{2}$ charge were also high and the percentage of removal of sterols is much lower than that observed for the $A$. mangium wood. Therefore, a complementary explanation might be related, with an easier removal of the oxidation products of $\Delta^{7}$ sterols formed during chlorine dioxide bleaching, when compared with the oxidation products of the corresponding $\Delta^{5}$ sterols (mainly $\beta$-sitosterol).

Fatty acids, particularly those $<\mathrm{C} 20$, are also extensively removed during pulping and ECF bleaching processes. The percentage of removal of fatty acids from the $A$. mangium wood was quite lower (around 20\%) than that observed for the other hardwoods 
( $\sim 60 \%$ for the E. urograndis, E. grandis and B. verrucosa wood and $40 \%$ for E. globulus wood), which can be directly related with the higher abundance of long chain fatty acids (> C20). Saturated fatty acids higher than C20 are the major fatty acids present in all bleached pulps (Fig. 5), which confirms that saturated fatty acids are very stable under the ECF bleaching conditions and that the fraction of fatty acids with less than C20 are relatively easily removed during pulping and bleaching stages.

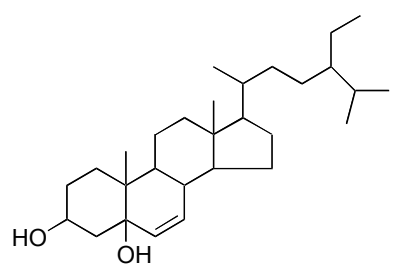

24-Ethyl-6-cholesten-3,5-diol

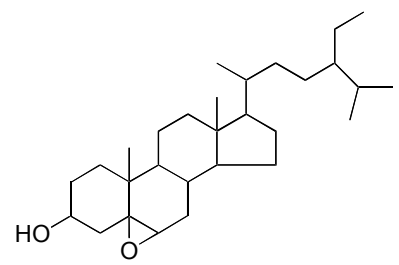

5,6-Epoxy-24-ethylcholestan-3-ol (5,6-Epoxy- $\beta$-sitosterol)

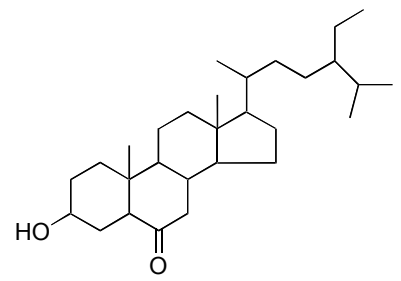

3-Hydroxy-24-ethylcholestan-6-one

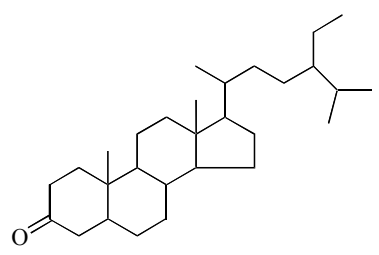

24-Ethylcholestan-3-one

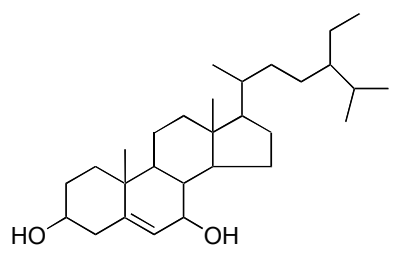

24-Ethyl-5-cholesten-3,7-diol (7-Hydroxy- $\beta$-sitosterol)

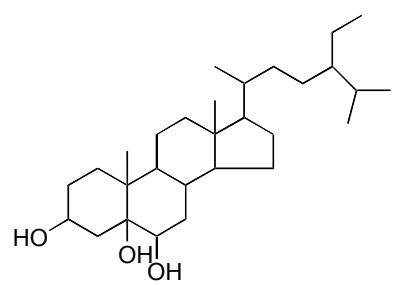

24-Ethylcholestan-3,5,6-triol

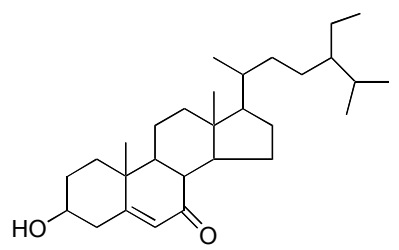

3-Hydroxy-24-ethyl-5-cholesten-7-one

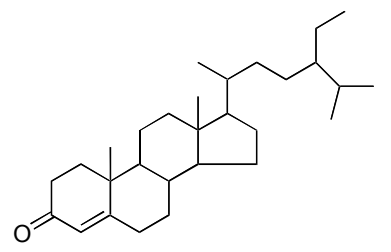

24-Ethyl-4-chlolesten-3-one<smiles>CCC(CCC(C)C1CCC2C3C(=O)C=C4C=CCCC4(C)C3CCC12C)C(C)C</smiles>

24-Ethyl-3,5-cholestedien-7-one

Fig. 4. Structures of the oxidized derivatives of sterols (mainly $\beta$-sitosterol) found in the DEDED bleached pulps. 
Unsaturated fatty acids, such as oleic and linoleic acids, are minor components of bleached pulps since they are easily oxidized during $\mathrm{ClO}_{2}$ bleaching (Freire et al. 2003). $\alpha$ - and $\omega$-hydroxy fatty acids (> C20) are also very stable under chlorine dioxide bleaching and are especially difficult to remove from pulps (Freire et al. 2003). These fatty acids represent an important fraction of Eucalyptus and A. mangium bleached pulps lipophilic extractive components (Table 3 ). The identification of the long chain hydroxy fatty acids in these bleached pulps is of particular importance because of their tendency for pitch formation, recently demonstrated in a Eucalyptus globulus ECF bleached kraft pulp mill (Silvestre et al. 1999; Freire et al. 2002b). There were no hydroxy fatty acids detected in the $B$. verrucosa bleached pulp because the major components of this family present in the corresponding wood have carbon chains lower than 16 atoms and, therefore, are easily removed during pulping and bleaching processes.

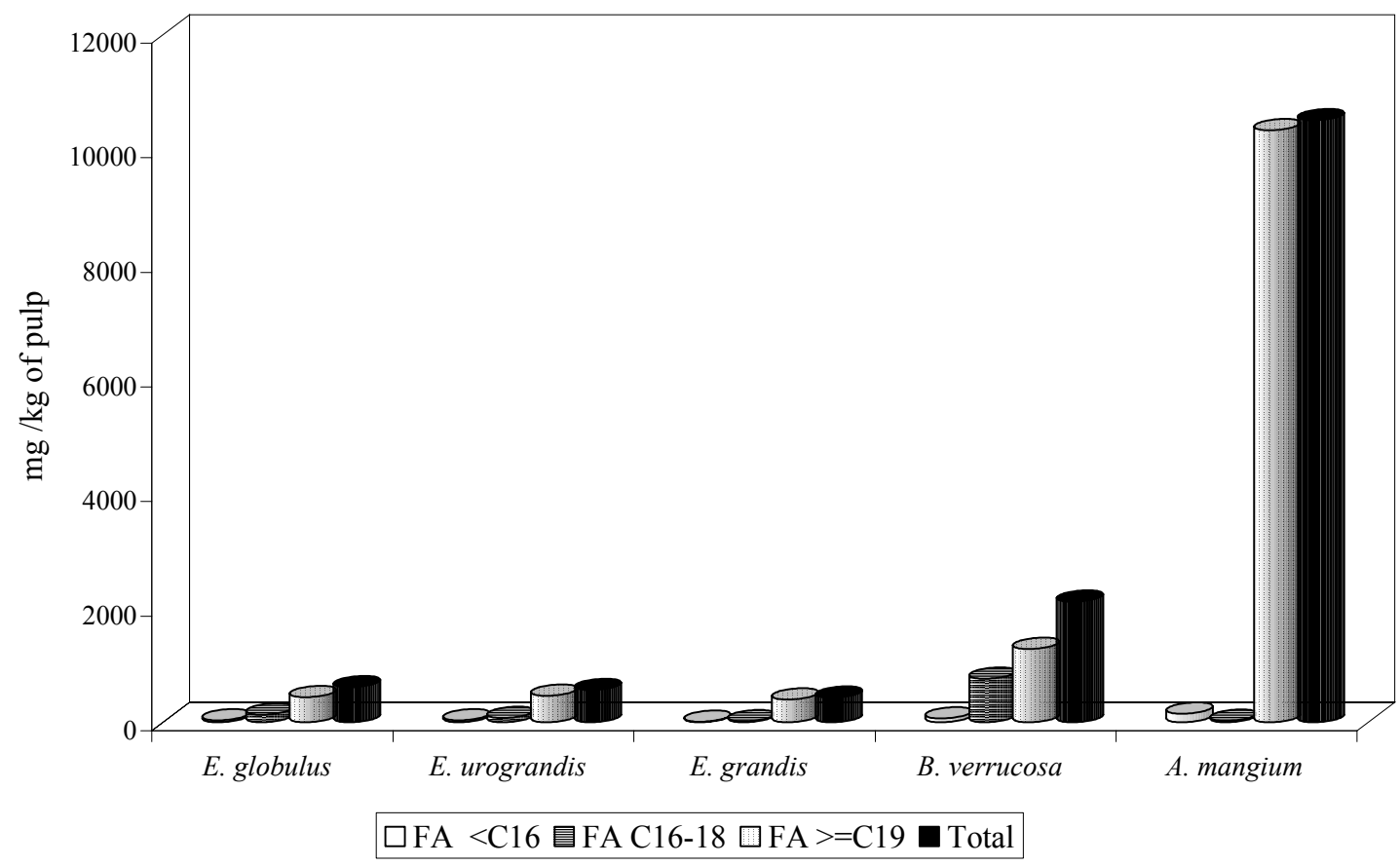

Fig. 5. Major fatty acids present in the acetone extracts of the hardwoods ECF bleached pulps. FA< C16 fatty acids with less than 16 carbon atoms; FA C16-C18 fatty acids with 16 to 18 carbon atoms and $F A>=19$ fatty acids with more than 19 carbon atoms.

As observed in woods, Eucalyptus and B. verrucosa bleached pulps contain small amounts of fatty alcohols, while in A. mangium bleached pulp, they represent the second most abundant family of lipophilic extractives. The removal of fatty alcohols from $A$. mangium wood $(10 \%)$ is also much lower than that observed for Eucalyptus and $B$. verrucosa woods (around 70\%,50\%,50\% and 70\%, respectively, for E. globulus, $E$. urograndis, E. grandis and B. verrucosa). Again, this is assigned to the fact that fatty alcohols with 24, 26 and 28 carbon atoms dominate in the A. mangium wood, and are more difficult to remove from wood than the fatty alcohols with a lower number of carbon atoms. 
Glycerides and other compounds such as ferulic acid and corresponding ferulates were not detected in the bleached pulps studied, certainly due to their complete removal and/or degradation during pulping and bleaching processes.

\section{CONCLUSIONS}

1. The lipophilic extractives of the hardwoods investigated (Eucalyptus globulus, Eucalyptus grandis, Eucalyptus urograndis, Betula verrucosa and Acacia mangium) are composed essentially of fatty acids (including $\alpha$ - and $\omega$-hydroxyacids), long chain aliphatic alcohols and sterols. The relative abundance and composition of these extractive families are significantly different in the various wood species. $B$. verrucosa is particularly rich in aliphatic acids $(<\mathrm{C} 22)$, mainly in free form, while $A$. mangium wood is very rich both in long chain $(>\mathrm{C} 20)$ aliphatic acids and aliphatic alcohols (in free and esterified forms).

2. During the kraft pulping of wood and pulp bleaching, using a chlorine dioxide based sequence, sterols are extensively removed (70-90\% for Eucalyptus, 50\% for B. verrucosa and $100 \%$ for $A$. mangium). The sterols fraction retained in bleached pulps are essentially $\beta$-sitosterol oxidation products and $\beta$-sitostanol. $\Delta^{7}$ sterols present in $A$. mangium are completely degraded and/or dissolved during the preparation of the bleached pulp. Fatty acids, particularly those $<\mathrm{C} 20$, are also removed in extents of 40 $60 \%$, except for $A$. mangium where about $80 \%$ are retained in bleached pulps. $\alpha$ - and $\omega$-hydroxy fatty acids ( $>$ C20) are highly retained in the bleached pulps.

3. Globally, B. verrucosa and $A$. mangium bleached pulps have a concentration of fatty acids approximately 4 and 20 times higher, respectively, than that of Eucalyptus pulps while the content of long chain aliphatic alcohols in $A$. mangium pulp is of the order of 100 times higher than Eucalyptus and B. verrucosa pulps. Such different amounts of lipophilic components certainly will induce significant differences in the surface energies of fibers, affecting their behavior during the papermaking process and the physico-mechanical properties of the final paper product (Kokkonen et al. 2002). In addition, long chain fatty acids, long chain fatty alcohols, hydroxy fatty acids and several sterol oxidation products are the lipophilic extractives with high tendency for pitch deposition (Ekman and Holmbom 2000; Freire et al. 2002b). In this context, $B$. verrucosa, and particularly, A. mangium, are the pulps with higher potential for pitch formation during the papermaking process.

\section{ACKNOWLEDGMENTS}

Thanks are due to FCT and ESF, within the Community Support Framework III, for the financial support of project POCTI CTM/34159/2000 and for the awarding of Ph.D. grants to C.S.R. Freire, P.C.R. Pinto and S. Santiago, to the Forest and Paper Research Institute RAIZ for supplying the Eucalyptus wood samples and collaboration in pulping and bleaching experiments and to Stora Enso and Kvaerner Pulping AB for supplying the Betula verrucosa and Acacia mangium woods, respectively. 


\section{REFERENCES CITED}

Artaud, J., Iatrides, M-C. and Gaydou, E. M. (1984). "Co-occurrence of $\Delta^{5}$ - and $\Delta^{7}$ sterols in two Gleditsia species. A reassessment of the sterols composition in oils rich in $\Delta^{7}$ sterols," Phytochem. 23(10), 2303-2306.

Back, E. L. and Allen, L. H. (Eds.) (2000). Pitch Control, Wood Resin and Deresination, Tappi Press, Atlanta.

Coleman, M. J. (1998). "Tropical forestry: Acacia plantations in Indonesia," Tappi J. 81(12), 43-49.

Combaut, G. (1986). "GC-MS on plant sterol analysis," Gas Chromatography/Mass Spectrometry, H. F. Linskens and J. F. Jackson, eds., Springer-Verlag, Berlin.

del Río, J. C., Gutiérrez, A., González-Vila, F. J., Martín, F. and Romero, J. (1998). "Characterization of organic deposits produced in kraft pulping of Eucalyptus globulus wood," J. Chromatog. A. 823(1-2), 457-465.

del Río, J. C., Romero, J. and Gutiérrez, A. (2000). "Analysis of pitch deposits produced in kraft pulp mills using a totally chlorine free bleaching sequence," J. Chromatog. A. 874(2), 235-245.

Ekman, R. (1983). "Suberin monomers and triterpenoids from the outer bark of Betula verrucosa EhrH," Holzforschung, 37(4), 205-211.

Ekman, R. and Holmbom, B. (2000). "The chemistry of wood resin," Pitch Control, Wood Resin and Deresination. E. L. Back and L. H. Allen (Eds.) Tappi Press, Atlanta (Chapter 2).

Freire, C. S. R., Silvestre, A. J. D. and Pascoal Neto, C. (2002a). "Identification of new hydroxy fatty acids and ferulic acid esters in the wood of Eucalyptus globulus," Holzforschung 56(2), 143-149.

Freire, C. S. R., Silvestre, A. J. D., Pereira, C. C. L., Pascoal Neto, C. and Cavaleiro, J. A. S. (2002b). "New lipophilic components of pitch deposits from an Eucalyptus globulus bleached Kraft pulp mill," J. Wood Chem. Technol. 22(1), 55-66.

Freire, C. S. R., Silvestre, A. J. D. and Pascoal Neto, C. (2003). "Oxidized derivatives of lipophilic extractives formed during hardwood kraft pulp bleaching," Holzforschung 57(5), 503-517.

Freire, C. S. R., Silvestre, A. J. D. and Pascoal Neto, C. (2005). "Lipophilic extractives in Eucalyptus globulus Kraft Pulps. Behaviour during ECF bleaching," J. Wood Chem. Technol. 25(1-2) 67-80.

Freire, C. S. R., Silvestre, A. J. D. and Pascoal Neto, C. and Evtuguin, D.V. (2006). "Effect of oxygen, ozone and hydrogen peroxide bleaching stages on the contents and composition of extractives of Eucalyptus globulus kraft pulps," Biores. Technol. 97(3), 420-428

Gutiérrez, A., del Río, J. C., González-Vila, F. J. and Martín, F. (1998). "Analysis of lipophilic extractives from wood and pitch deposits by solid-phase extraction and gas chromatography," J. Chromatogr. A 823(1-2), 449-455. 
Gutiérrez, A., del Río, J. C., González-Vila, F. J. and Martín, F. (1999). "Chemical composition of lipophilic extractives from Eucalyptus globulus Labill wood," Holzforschung 53(5), 481-486.

Gutiérrez, A., Romero, J. and del Río, J. C. (2001a). "Lipophilic extractives from Eucalyptus globulus pulp during kraft cooking followed by TCF and ECF bleaching," Holzforschung 55(3), 260-264.

Gutiérrez, A. and del Río, J. C. (2001b). "Gas Chromatography/ Mass Spectrometry demonstration of steryl glycosides in Eucalypt wood, kraft pulp and process liquids," Rapid Commun. Mass Spectrom. 15(24), 2515-2520.

Hillman, D. C. (2002). "Single-species pulping. The world's preferred market pulps," Solutions, Nov., 27-28.

Kokkonen, P., Korpela, A., Sundberg, A, Holmbom, B. (2002). 'Effects of different types of lipophilic extractives on paper properties," 17(4), 382-386.

Nilvebrant, N.-O and Byström, S. (1995). "Demonstration of glucosidic linked sterols in birch", Proceedings of the $8^{\text {th }}$ International Symposium on Wood and pulping Chemistry, Helsinki, Finland, Vol. II, pp. 135-140.

Pascoal Neto, C., Silvestre, A. J. D., Evtuguin, D., Freire, C. S. R., Pinto, P. C. R., Santiago, A. S., Fardim, P. and Holmbom, B. (2004). "Bulk and surface composition of ECF bleached hardwood kraft pulp fibres" Nord. Pulp Paper Res. J. 19(4), 513520.

Pietarinen, S., Willför, S. and Holmbom, B. (2003). "Wood resin in Acacia mangium and Acacia crassicarpa wood and knots," Appita J. 57(2), 146-150

Santos, G. G., Alves, J. C. N., Rodilla, J. M. L., Duarte, A. P., Lithgow, A. M. and Urones, J. G. (1997). "Terpenoids and other constituents of Eucalyptus globulus," Phytochem. 44(7), 1309-1312.

Silvestre, A. J. D., Pereira, C. C. L., Pascoal Neto, C., Evtuguin, D. V., Duarte, A. C., Cavaleiro, J. A. S. and Furtado, F. P. (1999). "Chemical composition of pitch deposits from an ECF Eucalyptus globulus bleached kraft pulp mill: its relationship with wood extractives and additives in process streams," Appita J. 52(5), 375-382.

Swan, B. and Åkerblom, I.-S. (1967). "Wood extractives from Eucalyptus globulus Labill," Svensk. Papperstidn. 70: 239-244.

Wallis, A. F. A. and Wearne, R. H. (1997). "Analysis of resin in eucalypt woods and pulps," Proc. $51^{\text {st }}$ Annual General Conference. Appita, Melbourne, Vol. I, pp. 45-50.

Article submitted: March 21, 2006; Accepted: April 29, 2006; Published: May 25, 2006 